\title{
Shelf-Stable Sustainable Shrimp Thermally Processed With Reciprocal Agitation
}

\author{
William R. Dixon ${ }^{1}$, Evelyn G. Watts ${ }^{1}$, John A. King ${ }^{2}$, Xing Fu ${ }^{3}$ and Louise Wicker ${ }^{1 *}$ \\ ${ }^{1}$ School of Nutrition and Food Sciences, Louisiana State University, Baton Rouge, LA, United States, ${ }^{2}$ Apis Group, Limited \\ Liability Company, Colbert, GA, United States, ${ }^{3}$ School of Animal Sciences, Louisiana State University, Baton Rouge, LA, \\ United States
}

OPEN ACCESS

Edited by:

Lourdes Maria Correa Cabral, Brazilian Agricultural Research Corporation (EMBRAPA), Brazil

Reviewed by:

Ravishankar Chandragiri Nagarajarao,

Central Institute of Fisheries

Technology (ICAR), India

Angela Aparecida Lemos Furtado,

Brazilian Agricultural Research

Corporation (EMBRAPA), Brazil

${ }^{*}$ Correspondence:

Louise Wicker

Iwicker@agcenter.Isu.edu

Specialty section:

This article was submitted to

Sustainable Food Processing,

a section of the journal

Frontiers in Sustainable Food Systems

Received: 05 June 2020

Accepted: 26 August 2020

Published: 06 October 2020

Citation:

Dixon WR, Watts EG, King JA, FuX and Wicker $L$ (2020) Shelf-Stable

Sustainable Shrimp Thermally

Processed With Reciprocal Agitation.

Front. Sustain. Food Syst. 4:569790.

doi: 10.3389/fsufs. 2020.569790
Shelf-stable, ready-to-eat shrimp offer a convenient, portion-controlled option for a highly desirable seafood commodity. The perishability of shrimp requires tight cold-temperature control during distribution and handling. Thermal processing of shrimp was evaluated in a multimode retort with automated control of come-up, heat, and cool times and with addition of high-speed reciprocal agitation. Reciprocal agitation was compared with static retort for thermal process and quality parameters, including cook time, process time to achieve target lethality $\left(F_{0}\right)$, cook yield, texture, and appearance of shelf-stable shrimp. Total retort thermal processing times decreased from 30 min at 0 shakes per minute (SPM) to $17.1 \mathrm{~min}$ at $180 \mathrm{SPM}$ to achieve same $F_{0}$. The time to reach targeted $F_{0}$ value of 6 min decreased by 29,37 , and $42 \%$ for 45,90 , and 180 SPM, respectively, compared with static retort thermal processing. The shrimp blanch yield was about 90\% and retort yield was 70-75\% after retort thermal processing for all retort runs $(0,45,90$, and 180 SPM). Shear force texture was significantly higher at all agitation speeds compared with static retort processing with values of 384,422 , and $475 \mathrm{~g}-\mathrm{F}$ with increasing agitation and $294 \mathrm{~g}-\mathrm{F}$ at static conditions. Increase surface sloughing and sedimentation was observed at higher agitation speeds. Oxygen headspace was under $1 \%$ for containers flushed with nitrogen, and the rigid plastic containers used for retort packaging were not adversely affected by either static or by reciprocal agitation up to 180 SPM. Thermal processing with reciprocal agitation at 90 or 180 SPM achieves similar $(p>0.05)$ shear force. Reciprocal agitation at 90 SPM is recommended for improved retort efficiency and increased textural quality of retorted shrimp. A sustainable, high-quality canned shrimp that can be stored at ambient temperature can be produced by reciprocal agitation retorts.

Keywords: shear force, shelf stable, canned, thermal processing, Farfantepenaeus aztecus, reciprocal agitation

\section{INTRODUCTION}

Global food waste is estimated at $33 \%$ or 1.3 billion tons per year and impacts the entire food system, with waste of land, water, and energy resources and preventable carbon dioxide emissions (FAO, 2015). Consumers in developed countries account for $28 \%$ of food waste, compared with $7 \%$ waste by consumers in developing countries (FAO, 2011a). In the USA, about $31 \%$ of the 430 billion pounds of food produced in 2010 was lost at the retail level, and the greatest loss was in the meat, 
poultry, and fish category at 30\% (Buzby et al., 2014), which points to critical need for interventions to reduce waste of animal-based foods. To reduce food waste, multistep recommendations across food systems include greater transparency, innovations in food manufacturing and packaging that extend shelf life, as well as intervention at the retail level with development of foods that meet consumer needs (www. FoodWasteAlliance.org; www.fao.org; www.ReFed.org).

Fisheries account for $17 \%$ of animal protein intake, and per capita consumption is over $20 \mathrm{~kg}$ fish. World fishery and aquaculture supplies are expected to increase to 200 million tons by 2030, pushing the need for sustainable production, processing, and distribution strategies (FAO, 2011b). Farmed shrimp operations in Asia provide a global shrimp supply, and China, India, and Viet Nam are the top 3 largest shrimp producers in the world (FAO, 2019a). Shrimp and prawns are in the top 3 imports in the USA (National Fisheries Institute (NFI), 2018). The harvest of brown shrimp (Farfantepenaeus aztecus) from the Gulf of Mexico was about 98.3 million kilograms and in Louisiana, the harvest was 42.1 million kilograms, valued at \$137.5 million (Louisiana Agriculture, 2017; National Marine Fisheries Service, 2018). The frozen and preserved values of shrimp are estimated at $\$ 5.2$ and $\$ 1.3$ billion, respectively (FAO, 2019b).

Innovations in processing and packaging of foods, especially animal-based foods, that retain high levels of nutrients and other quality attributes, with long shelf life, contributes to a balance between food security and food sustainability. Reliable and efficient processing improves operational efficiency within the food supply chain and reduces food waste (FAO, 2015). Chilled and frozen food products dominate the world market but require tight control of the cold distribution chain for food safety, quality, and shelf life. Preserved foods that do not rely on cold preservation offer the opportunity for lower energy costs during distribution and storage, more food security, and greater consumer convenience.

Thermal processing represents a significant proportion of the processed foods industry, allows extended shelf life of 1-5 years and energy savings associated with ambient temperature distribution and storage (Awuah et al., 2007). Shelf-stable foods are typically processed in cans, glass, flexible pouches, or rigid plastic, hermetically sealed, and processed with high temperature and pressure for a specified time to ensure destruction of target pathogens. Once processed, food safety risks associated with temperature fluctuations during storage are minimal for shelf-stable foods.

The global canned fisheries and seafood market, including tuna, salmon, sardines, shrimp, prawns, and other fisheries, were $\$ 21.5$ billion in 2016 and expected to grow due to greater interest in ready-to-eat foods and health benefits (www.grandviewresearch.com). The market size of the US canned food industry was estimated at $\$ 16.35$ billion in 2017; sustainable farming practices, ease of cooking, and increased shelf life contribute to the expected growth to $\$ 22.23$ billion by 2025 (www.grandviewresearch.com).

Shelf-stable foods are historically a staple in food service and after natural disasters and recognition of the convenience factor of in-container thermally processed foods is accelerating. At the food service level, availability of shelf-stable, ready-to-eat shrimp would improve on demand response in back-of-thehouse operations, avoid waste associated with overestimation of need and excess thawed shrimp or underestimation and need to rapidly thaw material. The development of ready-to-eat meals in single-served, portion-controlled, and calorie-controlled packages are popular. With the availability of high-quality, microwaveable, shelf-stable meal kits, meal planning, and preparation time are greatly reduced.

A severe limitation of any thermally processed food is the loss of quality attributes, such as texture, color, and flavor and nutritive value. Improved heat penetration compared with static processing was observed with oscillation at a $15^{\circ}$ angle with a $15 \mathrm{~s}$ hold (MacNaughton et al., 2018). The localized overprocessing at the package surface, high-energy costs, high water usage, and thermal process deviations have increased efforts for process and equipment optimization (Banga et al., 2003) and use of zero, first, biphasic, and Weibull mathematical models of quality to achieve food safety with minimal quality loss (Ling et al., 2015).

Reciprocal agitating retorts are a promising thermal process technology, which reduces process times, results in energy savings, and improves product quality (Singh and Ramaswamy, 2015). Reciprocal agitation in thermal processing is capable of extremely high longitudinal frequencies that rapidly shake the package back and forth; product movement in the package is much higher than observed with rotary or oscillating retorts (Walden, 2008). The package orientation and potential advantages of reciprocal agitation, vs. axial rotation, oscillation, or end-over-end agitation was described (Singh et al., 2018). For liquid foods or purees, reciprocal agitation increases heat penetration, reduces quality loss, and uses less energy (Walden, 2008). In tomato puree, a $63-81 \%$ reduction in process time with an improved retention of antioxidant activity, nutritive content, and color was obtained at $2 \mathrm{~Hz}$ (Singh and Ramaswamy, 2015). However, high-frequency reciprocal agitation severely disrupted the texture of potato and radish cubes in brine (You et al., 2016), and reduced frequency was needed to minimize integrity loss, leaching, and quality loss in green beans (Singh et al., 2016). Heat penetration of solid foods dispersed in fluid, heat slower than fluids or purees. Canned shrimp are expected to grow with compounded annual growth rate of $4.1 \%$ from 2017 to 2025 , attributed to high nutritional value, easily digestible protein, and use of shrimp in foodservice. Increasing quality of particulate muscle seafood, such as shrimp, would be advantageous. In this study, the objectives were to compare heat penetration and process times of reciprocal agitation and static retort thermal processing of brown shrimp packed in water. The cook yield and texture of brown shrimp were determined to assess quality of shrimp. In addition, shrimp were packaged in an oxygen barrier rigid plastic containers.

\section{MATERIALS AND METHODS \\ Shrimp and Container Preparation}

Louisiana Gulf Coast (LGC) brown shrimp (Farfantepenaeus azecus), which were phosphate treated, beheaded, peeled, and 
individually quick frozen in $2 \mathrm{~kg}$ bags, were obtained from Gulf Crown Seafood (Delcambre, LA, USA). Prior to using, shrimp were thawed for 3 days at $4^{\circ} \mathrm{C}$. Post-thaw, raw shrimp (7-9 shrimp/100 g) were drained and raw shrimp weight was measured before blanching. The shrimp were blanched in boiling water for $3 \mathrm{~min}$ at a ratio of 1:2, shrimp:water. Blanched shrimp were drained of excess water and immediately submerged in an ice slurry for $3 \mathrm{~min}$. Excess water from ice slurry was drained and blanched shrimp weight was measured to determine blanch shrimp yield. Sufficient shrimp were blanched to process two probed and two non-probed rigid plastic containers, each at 0 , 45, 90, and 180 SPM in retort. Shrimp were thermally processed in quadruplicate.

The retort packaging was polypropylene injection in-moldlabel (IML) oxygen barrier rigid plastic containers with a permeation rate of $<0.5 \mathrm{cc} / \mathrm{m}^{2} /$ day (Sonoco, Hartsville, South Carolina USA). Each package contained 10 blanched shrimp and water was added to adjust the final weight to $150 \mathrm{~g}$ and headspace of $\sim 0.85 \mathrm{~cm}$ :

\section{(1) Water weight $=(150-10$ shrimp weight $) g$}

Retort and total yield was calculated post-retort thermal processing. Retort yield represents the amount of shrimp shrinkage from retort processing, and total yield represents the combined yield after blanching and retort processing. Only nonprobed shrimp were used to make quality assessments.

Probed containers were hole punched at the geometric center with a C-12 lever-type can punch to insert $3.81 \mathrm{~cm}$ CNS needle thermocouples. For each probed container, one shrimp was attached in a particulate cage and lodged onto thermocouple to secure the needle thermocouple in shrimp at the center of the largest segment of the largest shrimp. Copper-constantan wires were used to connect the thermocouples to data logger. Thermocouple parts were purchased from Ecklund-Harrison Technologies Inc. (Fort Myers, FL USA).

Retort containers were sealed with a semiautomatic Control GMC (CGMC) PL200G (Boucherville, QC CA) with Bemis retort-grade L7288 film (Neenah, WI USA). The seal duration was set to $1.5 \mathrm{~s}(150 \times 0.01 \mathrm{~s})$. The nitrogen gas flush was set to $1 \mathrm{~s}$ $(100 \times 0.01 \mathrm{~s})$ with a gas pressure of $207 \mathrm{kPa}$ and a film length of $10.2 \mathrm{~cm}$. Nitrogen gas flush was used on half of the 64 rigid plastic containers and the other half did not have a nitrogen gas flush.

\section{Retort Thermal Processing Settings}

All samples were processed with a multimode Allpax $R \& D$ Retort 2402 Series with Shaka ${ }^{\circledR}$ technology (Covington, LA USA) in water spray-mode under static (0 SPM) and reciprocal agitation speeds of 45, 90, and 180 SPM. TechniCAL CALSoft 5 software and CALPLex data logger (Metairie, LA USA) were used to track heat penetration (time and temperature data throughout retort processing) and $F$ values (time in minutes required under specified conditions for a given food to destroy a known population of microorganisms, which is based on a reference temperature of $121.1^{\circ} \mathrm{C}$ and $z=10^{\circ} \mathrm{C}$ in current study) to determine lethality with the general and Ball's formula method (Goff, 2020).
The time to reach $F_{0}$ of $6.0 \mathrm{~min}$ was set to ensure commercial sterility as described in the literature and provided a control to analyze the effectiveness of each reciprocal agitation speed. Thermal process variables were based on averaged heat penetration data from four probed containers at each of the four shake speeds. Come-up was set to $10 \mathrm{~min}$. Pressure and atmospheric cooling were set to $10 \mathrm{~min}$ each. The overpressure was set to $241 \mathrm{kPa}$ during cook and ramped to atmospheric pressure during cooling. Only cook time to target $F_{0}$ of 6.0 and reciprocal agitation speeds were varied in the scheduled process.

Due to Ball's formula flexibility, Ball's formula parameters were compared for the target $F_{0}$ of 6.0 , obtained from the literature, with an initial product temperature of $4^{\circ} \mathrm{C}$ and retort temperature of $121.1^{\circ} \mathrm{C}$, to a target $F_{0}$ at $3.5 \mathrm{~min}$ after review of the NFPA guidelines recommending these conditions (National Food Processors Association, 1982). For Ball's formula method, the slowest heat penetration data of the probed samples, at each agitation speed was used to determine Ball's formula method variables and cook times $\left(B_{\mathrm{B}}\right.$ : Ball's cook time and $P_{\mathrm{t}}\left[B_{\mathrm{B}}-\right.$ (0.42*CUT)]: Ball's cook time with $42 \%$ come-up time credit) (Ramaswamy, 1993) using CalSoft5 "evaluate data/set a process" feature. Broken-line heating was used to improve fit of heat penetration data on semilogarithmic plot constructed in CalSoft5 software. Ball's formula method invariables include $j_{\mathrm{h}}, f_{\mathrm{h}}, f_{2}$, $x_{\mathrm{bh}}$, and $f_{\mathrm{c}}$, where $j_{\mathrm{h}}$ is the heating rate lag factor; $f_{\mathrm{h}}$ is the first slope heating rate index and $f_{2}$ is the second slope heating rate index of the semilogarithmic plotted heat penetration curve; $x_{\text {bh }}$ is time difference between the change in heating rate and corrected zero start time; $f_{\mathrm{c}}$ is the heating rate index during the cooling phase of processing. The cooling lag factor $\left(j_{\mathrm{c}}\right)$ was held constant at 1.41 (Stoforos, 2010; Singh et al., 2016). The critical factors included a maximum product fill weight of $150 \mathrm{~g}$, a horizontal orientation along axis of reciprocation of retort rigid plastic containers, and thermocouple position at geometric center of container and largest shrimp in container.

\section{Texture Analysis}

Shear force of shrimp was determined using a Warner-Bratzler shear $3 \mathrm{~mm}$ attachment blade (Stable Micro Systems TA.HD Plus texture analyzer, (TA) and Exponent software, Godalming, Surrey UK). Because the cooked shrimp had a curvature, the tail end of shrimp was trimmed to facilitate consistent placement of the second segment of the shrimp between Warner-Bratzler "V cut" slot and to avoid interference of last segments near the tail. Shrimp were placed on the texture analyzer mounting plate with head facing front and shrimp curving to the right. The texture analyzer settings were test mode, compression; pretest speed, $4.00 \mathrm{~mm} / \mathrm{s}$; test speed, $4.00 \mathrm{~mm} / \mathrm{s}$; post-test speed, $10.00 \mathrm{~mm} / \mathrm{s}$; distance, $13.500 \mathrm{~mm}$; and trigger force, $10.0 \mathrm{~g}$. Texture of shrimp was analyzed on packages with and without nitrogen flush.

\section{Controls From Commercial Sources}

Blanched LGC shrimp blanched on day of retorting was one control. Bumblebee's tiny canned shrimp (more than 65 shrimp/100g), containing salt, sugar, citric acid, sodium acid, pyrophosphate, calcium disodium EDTA, and sodium 
metabisulfite, was a second control. Bumblebee's medium canned shrimp (20-34 shrimp/100 g), containing salt, sugar, citric acid, sodium acid, pyrophosphate, calcium disodium EDTA, and sodium metabisulfite was a third control. The shrimp count for the controlled canned products were based on FAO guidelines for tiny and medium canned shrimp (FAO, 2013). A fourth control included Fisherman's Wharf ready-to-eat (RTE) cooked, frozen shrimp (5-7 shrimp/100 g). The RTE product contained salt and sodium tripolyphosphate. A fifth control was retail shrimp (5-7 shrimp/100 g), which was shrimp that was previously frozen and thawed before sale. For phosphate and other mineral analysis, individually quick frozen (IQF), no phosphate-treated Louisiana Gulf Coast brown shrimp (LGCnp, 7-9 shrimp/100 g), was also included.

\section{Oxygen and Carbon Dioxide Headspace Analysis}

Residual oxygen and carbon dioxide in headspace of retort containers were measured using a $5 \mathrm{~s}$ draw through a rubber septum (Systech Illinois GS6600 $\mathrm{O}_{2}$ and $\mathrm{CO}_{2}$, Illinois, IL USA). Containers were tilted to avoid solution contamination of needle.

\section{Inductively Coupled Plasma-Optical Emission Spectroscopy (ICP-OES) Mineral Analysis}

The LSU Agricultural Chemistry lab was used to determine phosphorous $(\mathrm{P})$ and other minerals in retorted shrimp and controls. Shrimp tails were removed, prior to analysis. Shrimp was freeze dried and ground (6875D Freezer/Mill ${ }^{\circledR}$ Dual Chamber Cryogenic Grinder, Metuchen, NJ USA) in a pre-cooled freezer/mill in three grinding cycles of $2 \mathrm{~min}$ each and a $1 \mathrm{~min}$ cool time at a rate of 10 cycles/s. For the canned shrimp (Bumblebee's tiny and medium canned shrimp) extraction, shrimp were drained and followed the same procedure $6875 \mathrm{D}$ Freezer/Mill operating manual for fish/seafood). Post-extraction, approximately $0.5 \mathrm{~g}$ of sample was placed in a Teflon microwave tube; $8 \mathrm{ml}$ of nitric acid and $2 \mathrm{ml}$ of hydrochloric acid were added. Sample was microwaved (CEM Mars 230 Microwave Digestor, Matthews, North Carolina USA) under a $20 \mathrm{~min}$ ramp up to $200^{\circ} \mathrm{C}$ and held for $20 \mathrm{~min}$. A Perkin Elmer 8300 ICP-OES analyzer (Waltham, MA USA) was used to determine mineral content.

\section{Statistical Analysis}

Mean, standard deviation, and coefficient of variation were computed; ANOVA analyses was conducted with Tukey HSD post-hoc test for measuring agitation significance with cook yield $(N=32)$ and texture analysis $(N=32)$ using JMP statistical software.

\section{RESULTS AND DISCUSSION}

The general method determines the lethality from the time/temperature profile for a specific food under the conditions utilized during the study. The Ball's formula method calculation of lethality allows extrapolation of heat penetration data from direct heat penetration data calculations. The method allows more flexibility in adjusting a scheduled process when retort temperature or initial product temperature are adjusted.

\section{Reciprocal Agitation, Processing Time, and $F_{0}$ - General Formula Method}

Average heat penetration curves, average retort temperature, and average $F_{0}$ values are depicted at agitation speeds of $0,45,90$, and 180 SPM (Figures 1, 2, 3, 4). The heat penetration curves truncate to shorter processing times as agitation increased from 0 to 180 SPM. Under static conditions, the retort temperature and shrimp heat penetration crossover after 25 min process time (Figure 1). Under $45 \mathrm{SPM}$, the time of crossover was $>15 \mathrm{~min}$ (Figure 2); at 90 and 180 SPM (Figures 3, 4), the times of crossover were $<15 \mathrm{~min}$. As agitation increased, heat penetration curves and retort temperature were more superimposable. At 180 SPM, temperature of probed shrimp was nearly the same temperature as the free retort lead.

Additionally, the accumulated $F_{0}$ value increased at a higher rate as the agitation speed increased from 0 to 180 SPM (Figures 1, 2, 3, 4). The time to achieve an $F_{0}$ value of 6.0 was about $60 \%$ shorter at 180 SPM than static (Figure 1). The times to achieve $F_{0}$ values of 6.0 decreased non-linearly from 30.0, 21.3, 19.0 to $17.3 \mathrm{~min}$ at $0,45,90$, and 180 SPM, respectively (Table 1).

Times associated with the CUT, cook time, cooling time, and total retort process time for each agitation speed are presented in Table 1. The CUT was set to $10 \mathrm{~min}$. Pressure and atmospheric cooling was set to $10 \mathrm{~min}$ each totaling to a cooling time of $20 \mathrm{~min}$ to ensure that final product temperature was $<40^{\circ} \mathrm{C}$ after cooling. The cook time decreased from 15.0, 7.7, 6.2 to $5.0 \mathrm{~min}$, as agitation increased from $0,45,90$ to $180 \mathrm{SPM}$, respectively. The accumulated $F_{0}$ achieved during heating and cooling as well as the total $F_{0}$ during the process are summarized (Table 1). Note that at higher agitation speeds, lethality was achieved primarily during cook with heat $F_{0}$ ranging between 63 and $75 \%$ of total $F_{0}$ for reciprocal agitation runs and $58 \%$ for static runs. At lower agitation speeds, a higher proportion of lethality of $42 \%$ was achieved during cooling for static runs, compared with the 25 and $37 \%$ range for reciprocal agitation runs. Total lethality was achieved 1.4 to 1.7 times faster with reciprocal agitation compared with static.

Similar decreases in time to achieve lethality was reported for béchamel sauce with sterilization methods that included static, rotary, and reciprocal agitation; reciprocal agitation achieved a target $F_{0}$ of 6 at 90 and $96 \%$ quicker than rotary and static, respectively (Walden and Emanuel, 2010). Improvements in process time were also observed in a canned tomato puree processed in a vertical steam reciprocating retort. The process time decreased from $43.4 \mathrm{~min}$ under static conditions to $8.1 \mathrm{~min}$ at $3 \mathrm{~Hz}$, which is equivalent to $180 \mathrm{SPM}$ (Singh et al., 2017). Overall, reciprocal agitation technology provided shorter process time than static retorts at all agitation speeds for process time and achieving target $F_{0}$ value.

\section{Ball's Formula Method}

The Ball's formula was implemented to determine heat penetration parameters with slowest heat penetration data and 


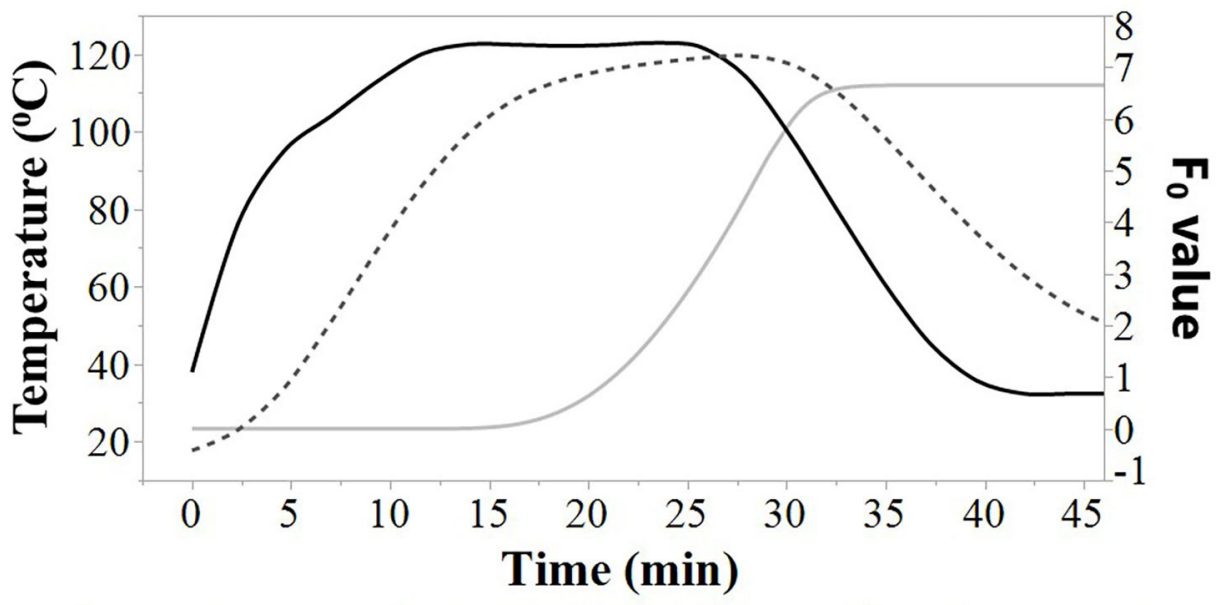

-Retort Temperature --Shrimp Heat Penetration - Shrimp Accumulated Fo

FIGURE 1 | Average retort temperatures (solid black), heat penetration curves (dotted black), and accumulated $F_{0}$ (solid gray) values for Louisiana Gulf Coast (LGC) brown shrimp during retort thermal processing at 0 SPM. JMP smoother function was used to construct all figure lines.

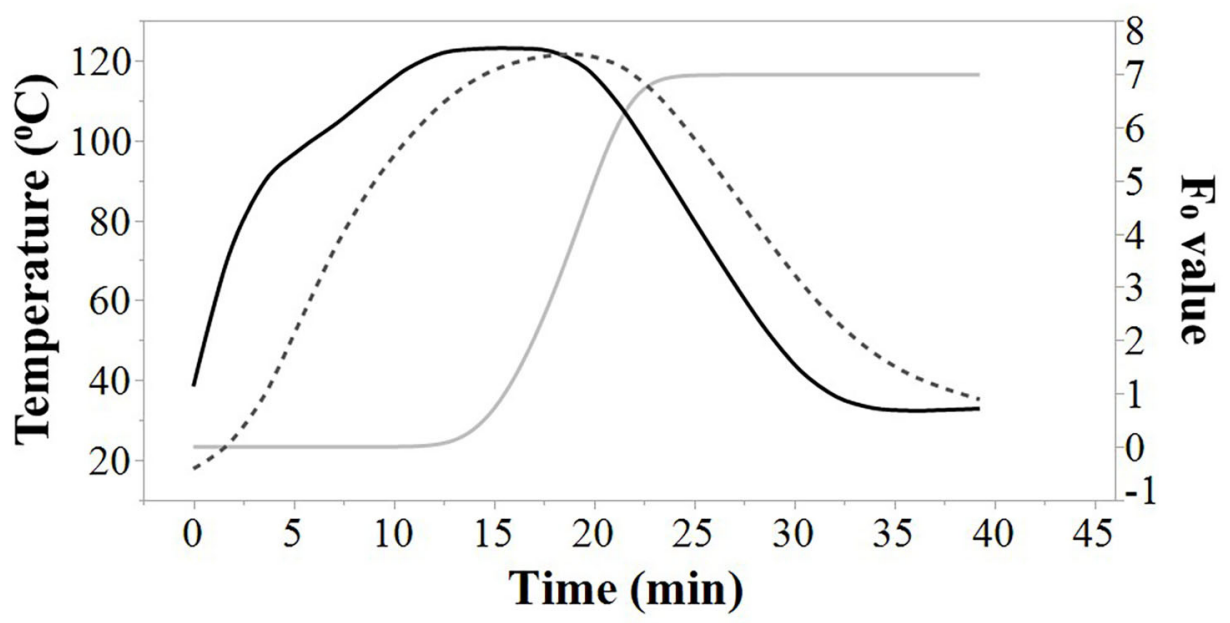

-Retort Temperature --Shrimp Heat Penetration - Shrimp Accumulated Fo

FIGURE 2 | Average retort temperatures (solid black), heat penetration curves (dotted black), and accumulated $F_{0}$ (solid gray) values for Louisiana Gulf Coast (LGC) brown shrimp during retort thermal processing at 45 SPM. JMP smoother function was used to construct all figure lines.

to compare Ball's parameters at $F_{0}$ values of 6.0 and 3.5. An $F_{0}$ of 3.5 was selected for further analysis based on referenced literature provided by a thermal process authority that provided a lethality $F_{0}$ value of 3.5 (National Food Processors Association, 1982). The cook times $\left(B_{\mathrm{B}}\right)$ were $25.7,16.3,13.6$, and $11.8 \mathrm{~min}$ for a $F_{0}$ value of 6.0 at $0,45,90$, and 180 SPM, respectively; cook times were 22.0, 13.5, 11.0, and $9.2 \mathrm{~min}$ for a $F_{0}$ value of 3.5 at $0,45,90$, and 180 SPM, respectively (Table 2). All Ball's formula factors decreased as agitation increased, except for Ball's heating factor $\left(f_{\mathrm{h}}\right)$, which increased from 45 to 90 SPM and decreased from 90 to 180 SPM; however, $180 \mathrm{SPM} f_{\mathrm{h}}$ was higher than 45 SPM. The shorter CUT between 45 SPM compared with 90 and 180 SPM almost certainly influenced the results by increasing the heating rate index to reach retort temperature. The total $F_{0}$ for all replications ranged from 6.28 to $7.93 \mathrm{~min}$. The $j_{\mathrm{h}}$ and $f_{\mathrm{h}}$ factors for all replications showed similar trends as the slowest heating probe. The $j_{\mathrm{h}}$ decreased with agitation at $0,45,90$, and $180 \mathrm{SPM}$ and mean values were 0.81 $\pm 0.10,0.49 \pm 0.05,0.38 \pm 0.03$, and $0.29 \pm 0.01$, respectively, indicating a favorable change in heating rate lag factor. At the same agitation speeds, the $f_{\mathrm{h}}$ factors were $11.84 \pm 0.38,11.21$ $\pm 0.58,10.02 \pm 0.38,9.42 \pm 0.38$, respectively. Both $B_{\mathrm{B}}$ and $P_{\mathrm{t}}$ process times decreased with agitation. The $B_{\mathrm{B}}$ and $P_{\mathrm{t}}$ values were $20.53 \pm 0.69$ and $15.70 \pm 0.69$, respectively, at $0 \mathrm{SPM}$ and decreased to $11.69 \pm 0.12$ and $686 \pm 0.12$, respectively at 180 SPM. 


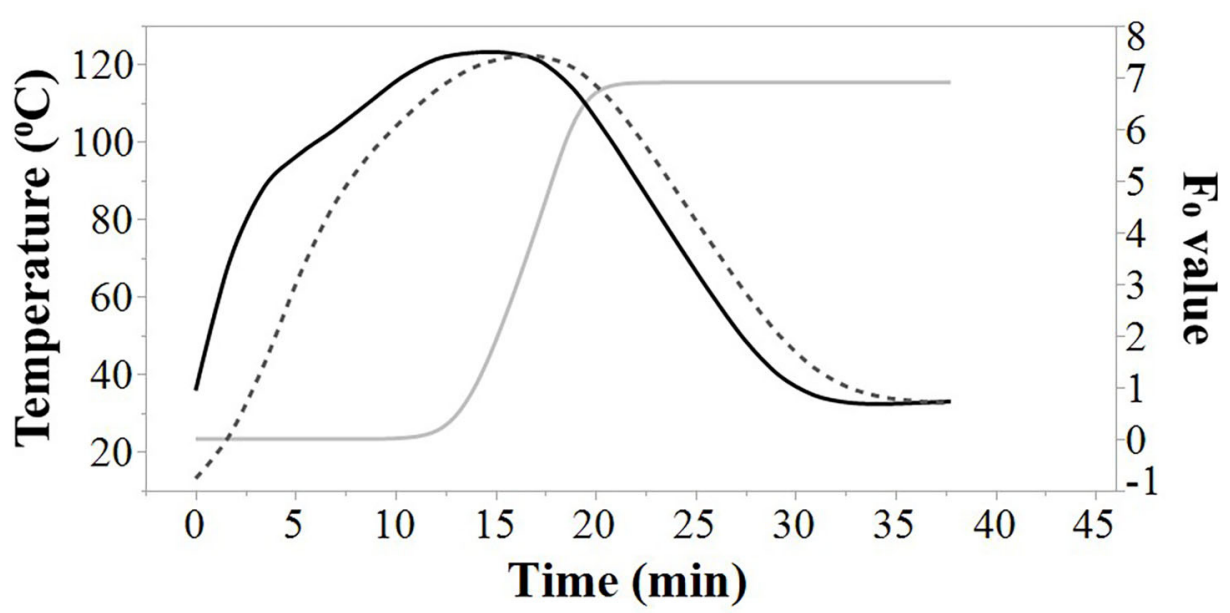

-Retort Temperature --Shrimp Heat Penetration -Shrimp Accumulated Fo

FIGURE 3 | Average retort temperatures (solid black), heat penetration curves (dotted black), and accumulated $F_{0}$ (solid gray) values for Louisiana Gulf Coast (LGC) brown shrimp during retort thermal processing at 90 SPM. JMP smoother function was used to construct all figure lines.

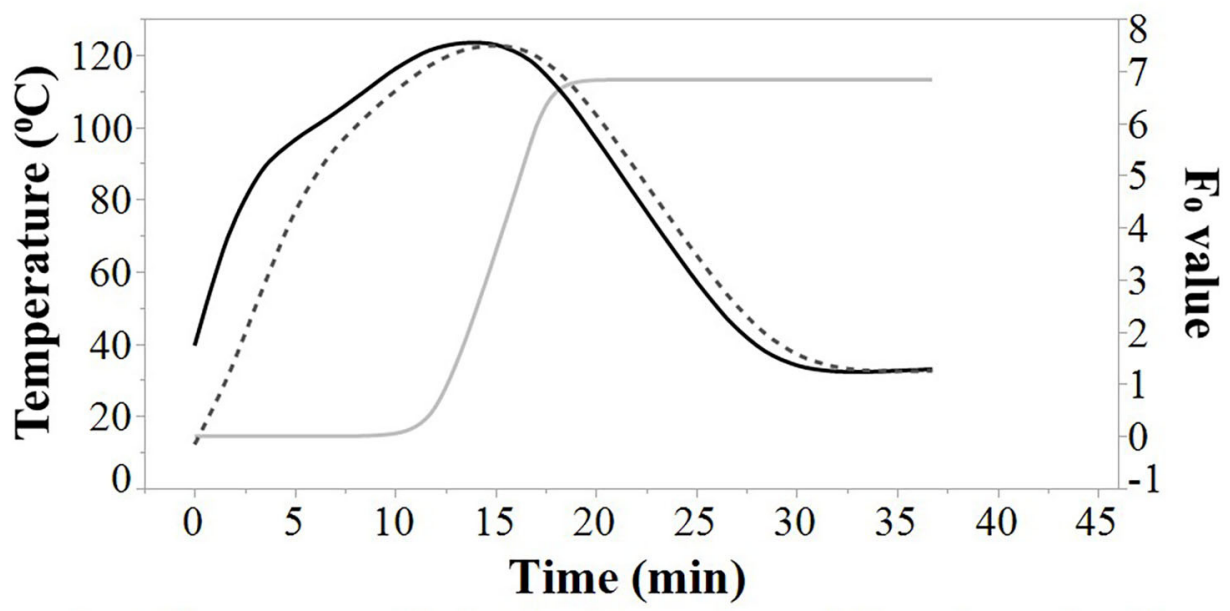

-Retort Temperature --Shrimp Heat Penetration - Shrimp Accumulated Fo

FIGURE 4 | Average retort temperatures (solid black), heat penetration curves (dotted black), and accumulated $F_{0}$ (solid gray) values for Louisiana Gulf Coast (LGC) brown shrimp during retort thermal processing at 180 SPM. JMP smoother function was used to construct all figure lines.

TABLE 1 | Retort settings and accumulated $F_{0}$ values at 0, 45, 90, and 180 SPM of retorted Louisiana Gulf Coast (LGC) brown shrimp using the general formula method $^{1,2}$.

\begin{tabular}{|c|c|c|c|c|c|c|c|c|c|}
\hline $\begin{array}{l}\text { Shakes per } \\
\text { min (SPM) }\end{array}$ & $\begin{array}{c}\text { Initial } \\
\text { product } \\
\text { temp }\left({ }^{\circ} \mathrm{C}\right)\end{array}$ & $\begin{array}{l}\text { Come-up } \\
\text { time (min) }\end{array}$ & $\begin{array}{l}\text { Cook time } \\
\text { (min) }\end{array}$ & $\begin{array}{l}\text { Cooling } \\
\text { time (min) }\end{array}$ & $\begin{array}{c}\text { Retort } \\
\text { process } \\
\text { time (min) }\end{array}$ & $\begin{array}{c}\text { Time } \\
\text { reached } \\
F_{0}=6 \\
\text { (min) }\end{array}$ & Heat $F$ & Cool $F$ & Total $F$ \\
\hline 0 & 20.2 & 10.0 & 15.0 & 20.0 & 45.0 & 30.0 & $4.0 \pm 0.7$ & $2.8 \pm 0.1$ & $6.8 \pm 0.7$ \\
\hline 45 & 22.1 & 10.0 & 7.7 & 20.0 & 37.7 & 21.3 & $4.4 \pm 0.5$ & $2.6 \pm 0.3$ & $7.0 \pm 0.4$ \\
\hline 90 & 20.4 & 10.0 & 6.2 & 20.0 & 36.2 & 19.0 & $4.6 \pm 0.3$ & $2.2 \pm 0.2$ & $6.8 \pm 0.3$ \\
\hline 180 & 20.3 & 10.0 & 5.0 & 20.0 & 35.0 & 17.3 & $5.1 \pm 0.2$ & $1.7 \pm 0.1$ & $6.8 \pm 0.1$ \\
\hline
\end{tabular}

Heat $F$, accumulated $F_{0}$ during CUT and cook time; Cool $F$, accumulated $F_{0}$ during cooling time; Total $F$, accumulated $F_{0}$ during retort process time.

${ }^{1}$ The overhead pressure was set to $241 \mathrm{kPa}$.

${ }^{2}$ Data represents the average heat penetration; initial temperature was controlled within $\pm 2{ }^{\circ} \mathrm{C}$; come-up time and cool time were controlled by Allpax software. 
TABLE 2 | Ball's formula method parameters, factors, and cook time using slowest heat penetration data for 0, 45, 90, and 180 SPM of retorted Louisiana Gulf Coast (LGC) brown shrimp ${ }^{1,2}$.

\begin{tabular}{|c|c|c|c|c|c|c|c|c|c|c|c|c|}
\hline \multirow[t]{2}{*}{ SPM } & \multicolumn{3}{|c|}{ Initial parameters } & \multicolumn{5}{|c|}{ Ball's formula factors ${ }^{3}$} & \multicolumn{2}{|c|}{$\begin{array}{l}\text { Process time (min) at } \\
\qquad F_{0}=3.5^{3}\end{array}$} & \multicolumn{2}{|c|}{$\begin{array}{l}\text { Process time }(\mathrm{min}) \text { at } \\
\qquad F_{0}=6\end{array}$} \\
\hline & CUT (min) & $\mathrm{RT}\left({ }^{\circ} \mathrm{C}\right)$ & IT $\left({ }^{\circ} \mathrm{C}\right)$ & $j_{\mathrm{h}}$ & $f_{\mathrm{h}}$ & $f_{2}$ & $\boldsymbol{f}_{\mathrm{c}}$ & $x_{\mathrm{bh}}$ & $B_{B}$ & $\mathbf{P t}$ & $B_{B}$ & $\mathrm{Pt}$ \\
\hline 0 & 11.3 & 121.1 & 4 & 1.1 & 12.2 & 15.2 & 12.2 & 13.6 & 22.0 & 17.3 & 25.7 & 21.0 \\
\hline 45 & 11.5 & 121.1 & 4 & 0.6 & 9.5 & 6.5 & 6.5 & 5.0 & 13.5 & 8.7 & 16.3 & 11.5 \\
\hline 90 & 11.3 & 121.1 & 4 & 0.4 & 10.2 & 3.7 & 3.7 & 5.0 & 11.0 & 6.3 & 13.6 & 8.8 \\
\hline 180 & 11.3 & 121.1 & 4 & 0.3 & 9.6 & 3.0 & 3.0 & 3.9 & 9.2 & 4.5 & 11.8 & 7.1 \\
\hline
\end{tabular}

$B_{B}$, Ball's cook time; $P_{t}$, Ball's cook time with come-up-time (CUT) credit.

${ }^{1}$ The overhead pressure was set to $241 \mathrm{kPa}$.

${ }^{2}$ Data represents the slowest heating probe.

${ }^{3} j_{c}$ was kept constant at 1.41 for all agitation speeds.

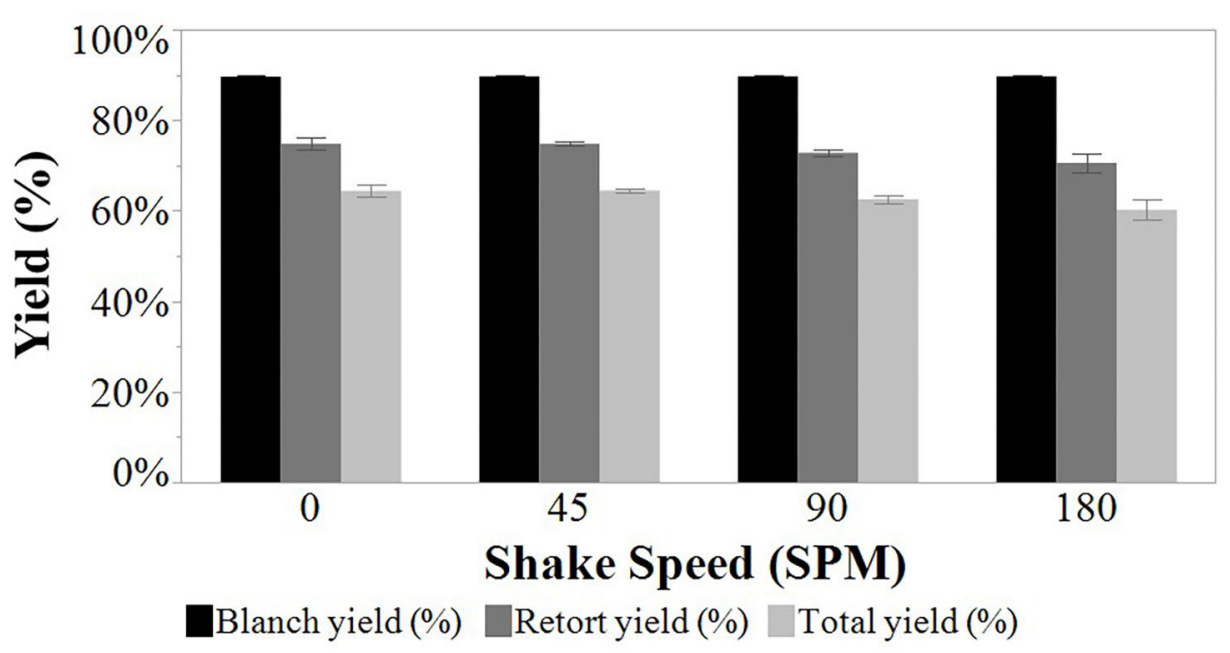

FIGURE 5 | Yield measured by weight relative to starting material. Louisiana Gulf Coast (LGC) brown shrimp used in the study. Blanched (LGC shrimp yield post-blanching raw LGC shrimp), retort (LGC shrimp yield post-retort processing blanch LGC shrimp), and total (LGC shrimp yield from blanch and retort shrinkage combined) yield of all non-probed LGC brown shrimp at 0, 45, 90, and 180 SPM.

Additionally, applying Ball's formula method (Table 2) showed a similar trend as the general formula method (Table 1) of decreased cook time as reciprocal agitation increased. Compared with Table 1 cook times, the Ball's formula method had higher cook times $\left(B_{\mathrm{B}}\right)$ for all agitation speeds at a $F_{0}$ value of 6.0 and 3.5. When come-up-time credit was considered during cook $\left(P_{\mathrm{t}}\right)$, only three of the four agitation speeds had higher general method cook times than the Ball's formula method at a $F_{0}$ value of 3.5. Overall, the processor could reduce the cook time by 2 to $4 \mathrm{~min}$ to achieve an $F_{0}$ of 3.5 ; the reduced time at retort temperature can have a significant impact on improving product quality (Stoforos, 2010; Erdogdu et al., 2016; Singh et al., 2017, 2018).

\section{Blanched and Retort Shrimp Yield}

Shrimp yield was evaluated after blanching and after retorting and total yield was reported (Figure 5). The average blanch yield was $90 \%$ for blanch batches. The retort yield averaged $73 \%$ for all agitation speeds and was not different $(p>0.05)$ for different reciprocal agitation speeds. The average total yield of $63 \%$ was also not different $(p>0.05)$. In comparison, yield of white shrimp after cooking in boiling water ranged between 70 and $85 \%$ (Erdogdu et al., 2004), 77 and 90\% (Niamnuy et al., 2007), and 59 and $87 \%$ (Carneiro et al., 2013). The LGC brown shrimp blanch yield was within the range of earlier studies.

In post-retort processed shrimp in the rigid plastic package, intact pieces of shrimp were observed, with some evidence of increasing surface sloughing with reciprocal agitation (Figures 6, 7). Marked differences were observed in shrimp that were drained (Figure 8); shrimp size decreased from blanched, non-retorted shrimp, to retorted shrimp with increased reciprocal agitation. Additionally, the amount of sedimentation increased with reciprocal agitation speeds from 0 to 180 SPM (Figure 9). Overall, the information collected provided additional visual confirmation of the impact of agitation speed and yield. 


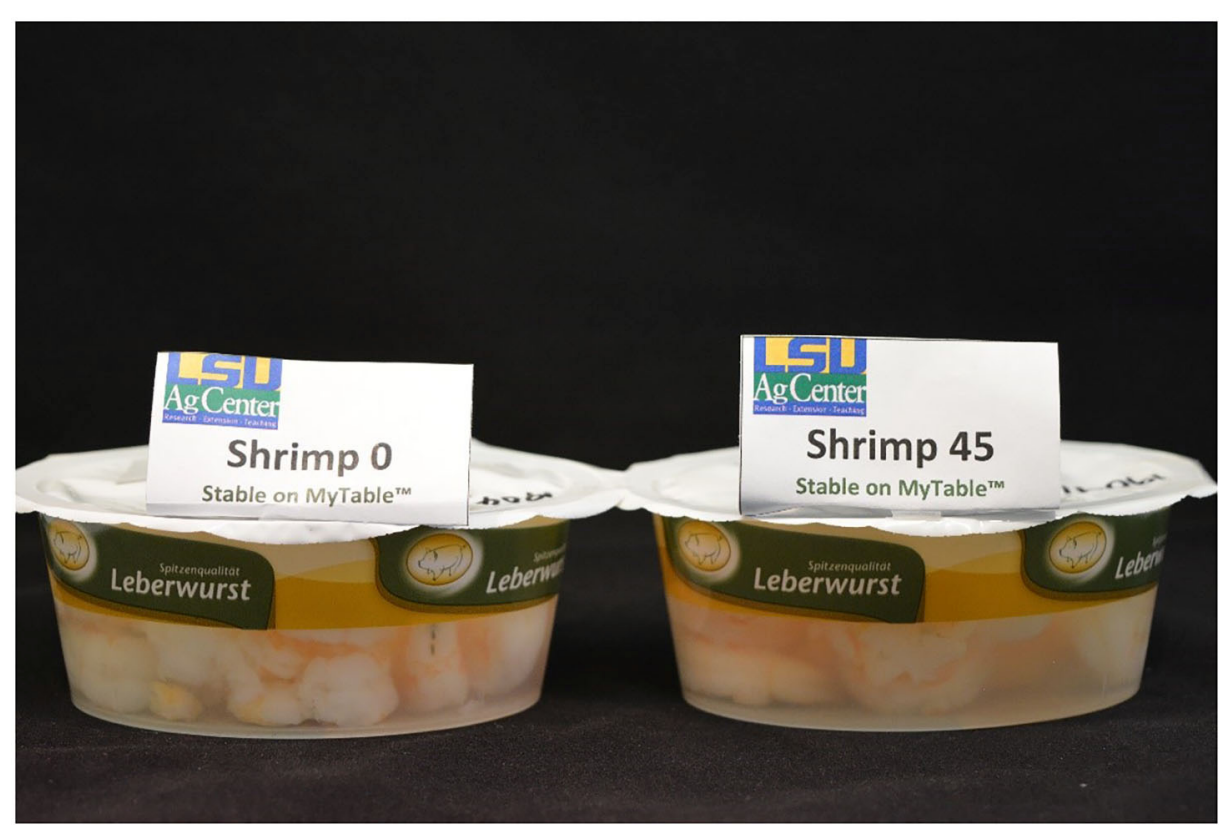

FIGURE 6 | Post-retort thermally processed Louisiana Gulf Coast (LGC) brown shrimp in retort containers at 0 and 45 SPM.

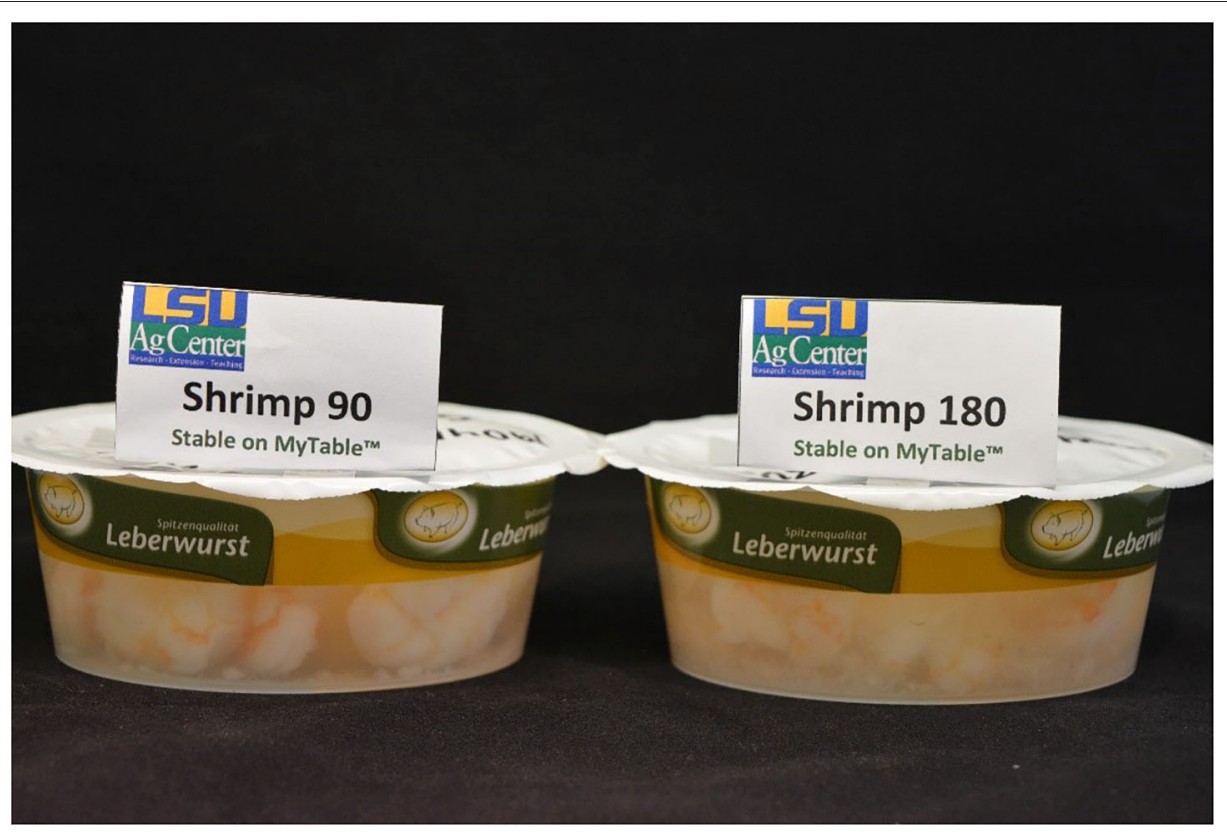

FIGURE 7 | Post-retort thermally processed Louisiana Gulf Coast (LGC) brown shrimp in retort containers at 90 and 180 SPM.

\section{Texture Analysis}

The shear force values of commercially available canned or frozen shrimp and shrimp evaluated in this study are presented in Table 3. The shear force of shrimp processed at four agitation speeds ranged between 294 and 475 g-F and increased with increased agitation (Table 3). Shear force was significantly $(p<0.05)$ higher from shrimp processed at 0 or 45 SPM and shrimp processed at 45 or 180 SPM. There was no difference $(p>0.05)$ in shrimp processed at 90 and 180 SPM. Shear force of shrimp processed under any agitation speed was significantly higher than no agitation. Although slightly smaller shrimp size, more pieces, and more sedimentation were observed with 


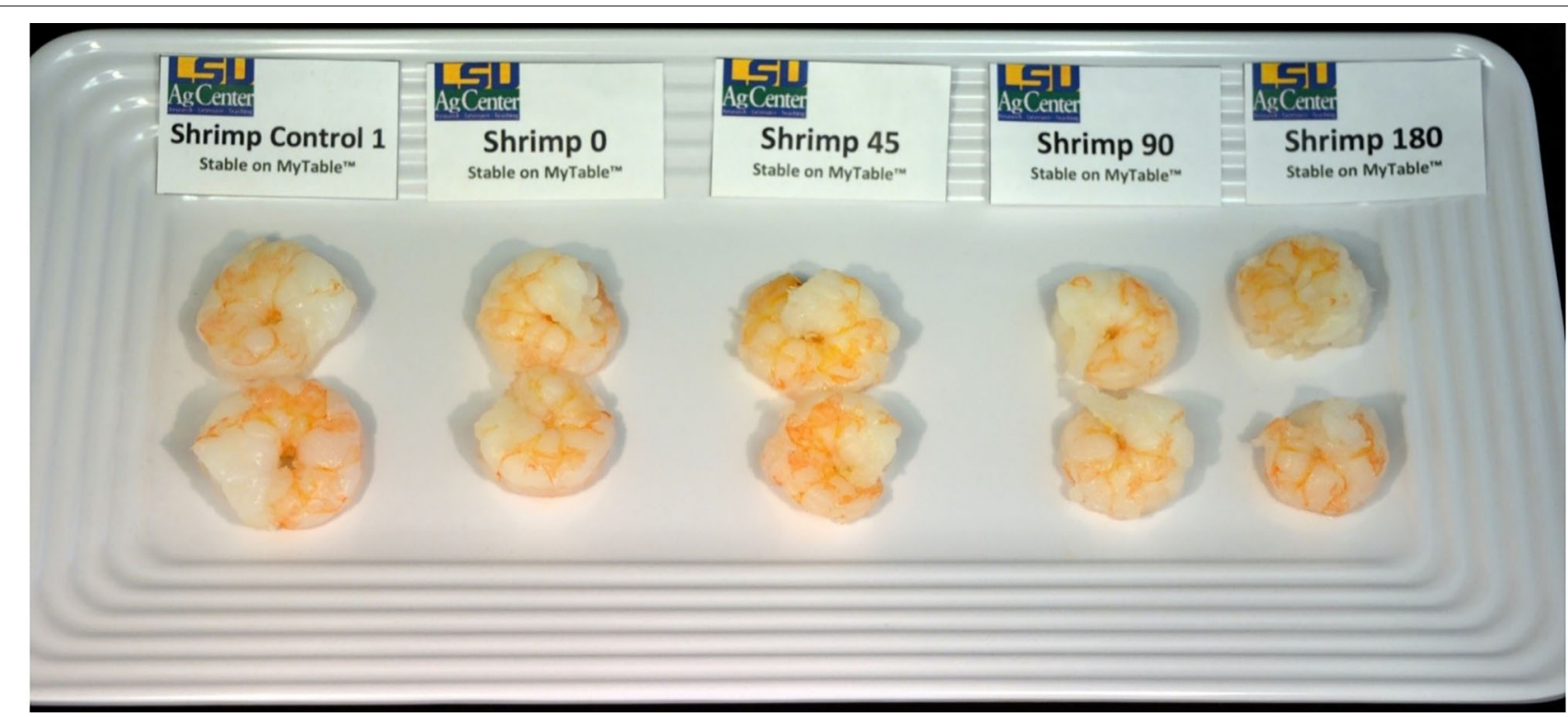

FIGURE 8 | Unprocessed, blanched Louisiana Gulf Coast (LGC) brown shrimp (control 1) compared with retort thermally processed LGC brown shrimp at 0, 45, 90, and 180 SPM.

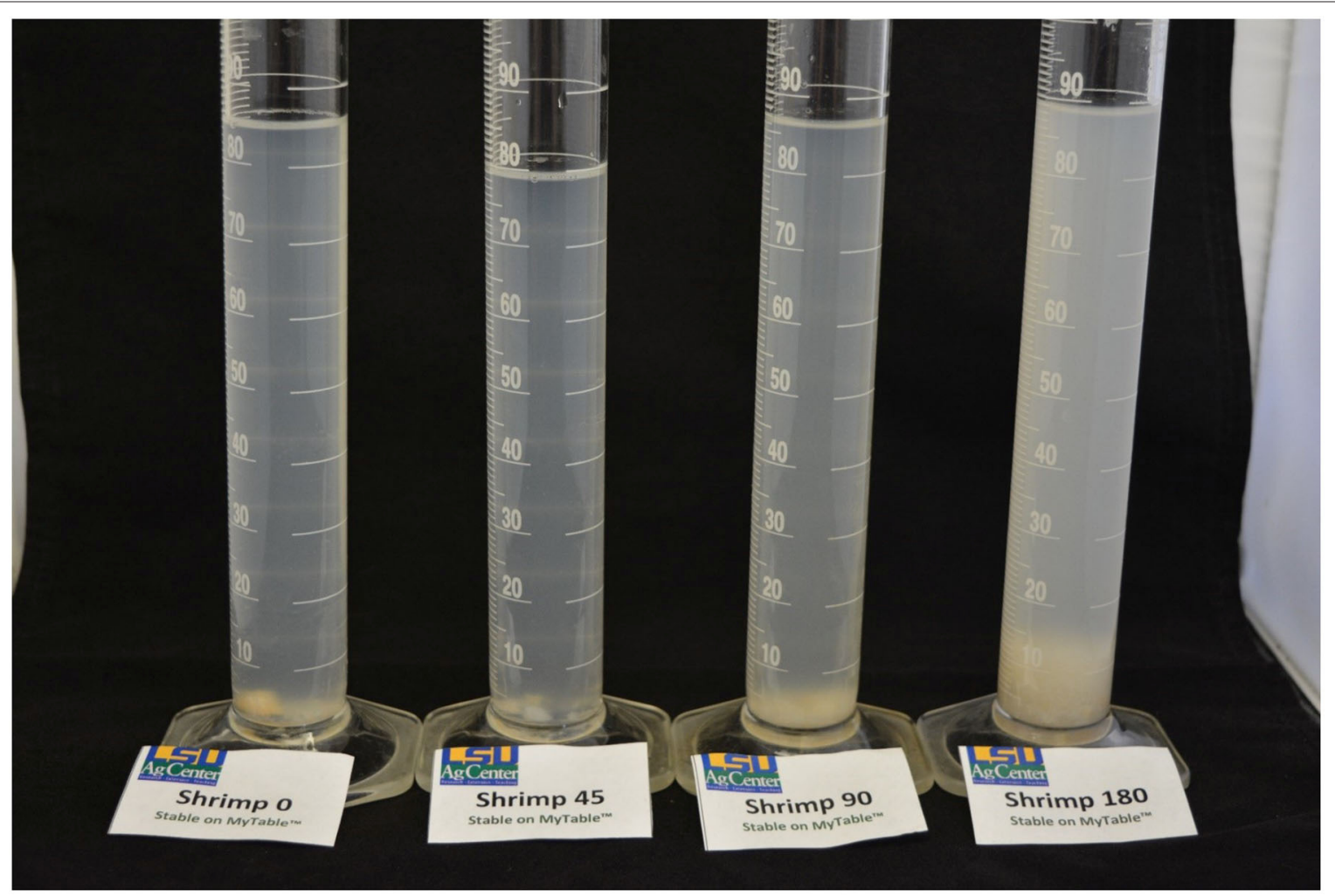

FIGURE 9 | Louisiana Gulf Coast (LGC) brown shrimp filtrate and sediment, retort thermally processed at 0, 45, 90, and 180 SPM.

higher agitation speeds, the data showed that 90 SPM agitation speed achieve increased shear force and minimal changes in shrimp appearance.
Shear force is a common textural analysis method used for determining firmness that is noted in many studies (Sreenath et al., 2008; Mallick et al., 2010; Majumdar et al., 
TABLE 3 | Firmness of commercial shrimp and in-house retort-processed Louisiana Gulf Coast (LGC) brown shrimp.

\begin{tabular}{|c|c|c|c|c|c|c|c|c|c|}
\hline \multirow[t]{2}{*}{ Texture (g-F) } & \multicolumn{6}{|c|}{ Retort processed (g-F) } & \multicolumn{3}{|c|}{ Non-retort processed (g-F) } \\
\hline & $\begin{array}{l}\text { Tiny canned } \\
\text { shrimp }^{1}\end{array}$ & $\begin{array}{l}\text { Medium } \\
\text { canned } \\
\text { shrimp }^{2}\end{array}$ & $\begin{array}{c}0 \text { SPM LGC } \\
\text { shrimp }^{3}\end{array}$ & $\begin{array}{c}45 \text { SPM LGC } \\
\text { shrimp }^{3}\end{array}$ & $\begin{array}{c}90 \text { SPM LGC } \\
\text { shrimp }^{3}\end{array}$ & $\begin{array}{l}180 \text { SPM } \\
\text { LGC } \\
\text { shrimp }\end{array}$ & $\begin{array}{l}\text { LGC shrimp } \\
\text { (blanched) }^{4}\end{array}$ & $\begin{array}{c}\text { Thawed } \\
\text { shrimp } \\
\text { (blanched) }^{5}\end{array}$ & RTE shrimp ${ }^{6}$ \\
\hline Mean & 600 & 691 & $294^{\mathrm{A}}$ & $384^{\mathrm{B}}$ & $422^{\mathrm{BC}}$ & $475^{\mathrm{C}}$ & 1,087 & 1,227 & 2,381 \\
\hline SD & 168 & 174 & 50 & 65 & 67 & 83 & 197 & 175 & 315 \\
\hline CV & 28 & 25 & 17 & 17 & 15 & 17 & 18 & 14 & 13 \\
\hline $\begin{array}{l}{ }^{1} \text { Bumblebee's tin } \\
{ }^{2} \text { Bumblebee's me } \\
{ }^{3} \text { Seven to nine st } \\
\text { thawed and bland } \\
(p<0.05) \text {. } \\
{ }^{4} \text { Seven to nine sh } \\
{ }^{5} \text { Five to seven sh } \\
{ }^{6} \text { Five to seven sh }\end{array}$ & $\begin{array}{l}\text { y canned shrimp } \\
\text { edium canned shri } \\
\text { hrimp } / 100 \mathrm{~g}, \text { IQF p } \\
\text { ched. Shaded are } \\
\text { hrimp } / 100 \mathrm{~g} \text {, IQF p } \\
\text { rimp } / 100 \mathrm{~g} \text {, retail }\end{array}$ & $\begin{array}{l}\text { re than } 65 \text { sh } \\
\text { (20-34 shrin } \\
\text { sphate-treate } \\
\text { apresents bla } \\
\text { sphate-treate } \\
\text { mp that were }\end{array}$ & $\begin{array}{l}\text { p/100 g). } \\
\text { (100 g). } \\
\text { Gulf Crown Seafo } \\
\text { ned LGC brown s } \\
\text { aulf Crown Seafoc } \\
\text { eviously frozen, th }\end{array}$ & $\begin{array}{l}d \text { brown shrimp fr } \\
\text { rimp that were ret } \\
\text { d brown shrimp fro } \\
\text { awed for sale, and }\end{array}$ & $\begin{array}{l}\text { m Louisiana Gulf } \\
\text { ort processed. Diff } \\
\text { m Louisiana Gulf } C \\
\text { blanched. }\end{array}$ & $\begin{array}{l}\text { oast ( } L G C) \text { us } \\
\text { ent upper cas } \\
\text { ast ( } L G C) \text {, blar }\end{array}$ & $\begin{array}{l}\text { for retort study a } \\
\text { etters in the same } \\
\text { hed only. }\end{array}$ & $\begin{array}{l}0,45,90, \text { and } 18 \\
\text { row indicate sign }\end{array}$ & $\begin{array}{l}\text { SPM, that was } \\
\text { icant differences }\end{array}$ \\
\hline
\end{tabular}

2017);(Shah et al., 2017). In retorted shrimp, a shear force range between 1,000 and $1,300 \mathrm{~g}-\mathrm{F}$ was observed when processing shrimp in pouches in a static retort at 6,8 , and 9 min $F_{0}$ values (Majumdar et al., 2017). Lower values between 700 and 900 gF were reported when shrimp were processed in pouches with an autoclave at 5, 7, and 9 min $F_{0}$ values (Mallick et al., 2010). Additionally, between 510 and 663 g-F was reported in shrimp processed in steel cans in a static retort at 6,7 , and $8 \mathrm{~min} F_{0}$ values (Sreenath et al., 2008). Although absolute values of firmness varied, lower $F_{0}$ values resulted in higher shear force in all studies. In the current study, shear force was lower than reported in the literature results. Variation in the shear force across studies likely results from variables such as equipment used, target $F_{0}$, type, size, and post-harvest age of shrimp, pre-treatment of shrimp, such as blanching, presence and concentration of phosphate, sulfites, or other ingredients (Byun et al., 2010; Hassan and Ramaswamy, 2013).

Shear force of commercially available shrimp products are reported (Table 3). As a blanched only, before retort control, the shear force of LGC shrimp was 1,087 g-F, about four times firmer than shrimp processed in static retort and about twice as firm as shrimp processed with reciprocal agitation at 180 SPM (Table 3). Thawed, blanched shrimp obtained from retail stores were similar in shear force at 1,227 $\mathrm{g}$-F as blanched LGC shrimp control, 1,087 g-F. A fully cooked, ready-to-eat thawed shrimp had a shear force value of 2,381 g-F, which is more than double the value of the blanched, LGC shrimp control. The difference cannot be attributed to phosphate content as phosphate levels are higher in LGC shrimp than RTE shrimp (Table 4). It may be that toughening resulted from supply chain handling, multiple freeze/thaw cycles prior to cooking, refreezing, and distribution of this fully cooked product. Shear force of commercial, tiny and medium size, retorted shrimp was 600 and $691 \mathrm{~g}-\mathrm{F}$, respectively (Table 3). The commercial canned shrimp were smaller with a shrimp count between 20 and more than 65 shrimp/100 g, compared with seven to nine shrimp count $/ 100 \mathrm{~g}$ for LGC shrimp. By qualitative visual and tactile assessment, the commercial retort shrimp showed obvious disintegration and failed in handling for sample analysis. In addition, the commercial retort shrimp and the ready-to-eat, cooked shrimp had an extensive ingredients list that may have contributed to the texture values. While the comparisons with commercial products cannot be used directly, the data clearly shows the benefit of reciprocal agitation to texture in this study.

\section{Headspace Analysis}

The headspace was $\sim 0.85 \mathrm{~cm}$ for all containers. Headspace is a crucial critical factor in reciprocal agitating retorts in regard to heat penetration, especially at high agitation speeds (Singh and Ramaswamy, 2015). The oxygen content was $80 \pm 13.2 \mathrm{mg} / \mathrm{g}$ and $4.7 \pm 2.7 \mathrm{mg} / \mathrm{g}$ for control, no nitrogen flush, and nitrogen flush, respectively. Carbon dioxide was $3.6 \pm 1.2 \mathrm{mg} / \mathrm{g}$ and 5.5 $\pm 0.9 \mathrm{mg} / \mathrm{g}$ for control, no nitrogen flush, and nitrogen flush, respectively. A target of $<10 \mathrm{mg} / \mathrm{g}$ oxygen is desired in retort foods. High oxygen levels negatively impacts food quality making it crucial to control during packaging (Bonilla et al., 2012).

\section{Mineral Analysis}

Mineral analysis (B, Ca, Cu, Fe, Mg, Mn, P, K, Na, S, and Zn) of five types of shrimp evaluated in this study is shown in Table 4. The amount of phosphorous in LGCnp and LGC brown shrimp with phosphate (LGC) was essential data to estimate phosphate levels of the LGC brown shrimp used for this study. LGC brown shrimp were treated with a phosphate brine during chilling on ship at sea. The type, concentration, solubility, and time of treatment with phosphate were not known. With access to LGC and LGCnp brown shrimp, the phosphorous levels were determined. LGCnp had $1.17 \mathrm{mg} / \mathrm{g}$ compared with LGC of $3.17 \mathrm{mg} / \mathrm{g}$, respectively. Although there can be a wide variety of natural occurring phosphorus in shrimp (Heitkemper et al., 1993), the mineral analysis confirmed that phosphate treatment resulted in a measurable increase in phosphorus content in the LGC brown shrimp compared with LGCnp brown shrimp.

Additionally, the amount of phosphorous in tiny and medium canned shrimp was 2.33 and $2.19 \mathrm{mg} / \mathrm{g}$, respectively. The RTE shrimp had $2.11 \mathrm{mg} / \mathrm{g}$. The mineral profiles were similar except 
TABLE 4 | ICP-OES mineral analysis of the retort-processed and non-retort-processed shrimp.

\begin{tabular}{|c|c|c|c|c|c|c|c|c|c|c|c|c|}
\hline Samples ${ }^{1}$ & $\begin{array}{c}\text { Mean } \\
\text { SD }\end{array}$ & $\begin{array}{c}P \\
(\mathrm{mg} / \mathrm{g})\end{array}$ & $\begin{array}{c}\mathrm{Ca} \\
(\mathrm{mg} / \mathrm{g})\end{array}$ & $\begin{array}{c}\mathrm{Mg} \\
(\mathrm{mg} / \mathrm{g})\end{array}$ & $\begin{array}{c}\mathrm{K} \\
(\mathrm{mg} / \mathrm{g})\end{array}$ & $\begin{array}{c}\mathrm{Na} \\
(\mathrm{mg} / \mathrm{g})\end{array}$ & $\begin{array}{c}\mathrm{S} \\
(\mathrm{mg} / \mathrm{g})\end{array}$ & $\begin{array}{c}\text { B } \\
(\mathrm{mg} / 100 \mathrm{~g})\end{array}$ & $\begin{array}{c}\mathrm{Cu} \\
(\mathrm{mg} / 100 \mathrm{~g})\end{array}$ & $\begin{array}{c}\mathrm{Fe} \\
(\mathrm{mg} / 100 \mathrm{~g})\end{array}$ & $\begin{array}{c}M n \\
(\mathrm{mg} / 100 \mathrm{~g})\end{array}$ & $\begin{array}{c}\mathrm{Zn} \\
(\mathrm{mg} / 100 \mathrm{~g})\end{array}$ \\
\hline \multirow[t]{2}{*}{ LGCnp } & Mean & 1.17 & 0.54 & 0.29 & 0.69 & 1.53 & 1.85 & 1.81 & 0.41 & 2.11 & 0.41 & 0.89 \\
\hline & SD & 0.06 & 0.24 & 0.00 & 0.03 & 0.06 & 0.05 & 0.21 & 0.00 & 0.32 & 0.00 & 0.06 \\
\hline \multirow[t]{2}{*}{ LGC } & Mean & 3.17 & 0.48 & 0.19 & 0.31 & 4.90 & 1.45 & 1.60 & 0.40 & 1.78 & 0.40 & 0.60 \\
\hline & $\mathrm{SD}$ & 0.37 & 0.03 & 0.01 & 0.05 & 0.64 & 0.03 & 0.00 & 0.00 & 0.26 & 0.00 & 0.00 \\
\hline \multirow[t]{2}{*}{ RTE } & Mean & 2.11 & 0.38 & 0.21 & 0.89 & 4.68 & 1.69 & 1.65 & 0.41 & 0.63 & 0.41 & 0.82 \\
\hline & SD & 0.21 & 0.05 & 0.02 & 0.12 & 0.56 & 0.14 & 0.04 & 0.01 & 0.32 & 0.01 & 0.01 \\
\hline \multirow[t]{2}{*}{ Tiny canned } & Mean & 2.33 & 2.04 & 0.37 & 0.17 & 4.56 & 2.79 & 1.60 & 0.41 & 2.19 & 0.40 & 0.46 \\
\hline & $\mathrm{SD}$ & 0.06 & 0.09 & 0.02 & 0.01 & 0.07 & 0.02 & 0.00 & 0.01 & 0.60 & 0.00 & 0.02 \\
\hline \multirow{2}{*}{$\begin{array}{l}\text { Medium } \\
\text { canned }\end{array}$} & Mean & 2.19 & 1.72 & 0.51 & 0.19 & 4.41 & 2.57 & 1.60 & 0.56 & 2.04 & 0.40 & 1.42 \\
\hline & $\mathrm{SD}$ & 0.33 & 0.26 & 0.12 & 0.00 & 0.11 & 0.00 & 0.00 & 0.03 & 0.54 & 0.00 & 0.14 \\
\hline
\end{tabular}

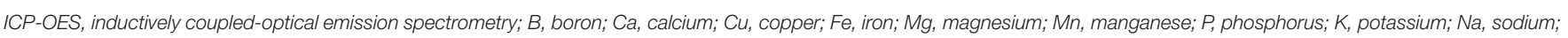
$S$, sulfur; $Z n$, zinc.

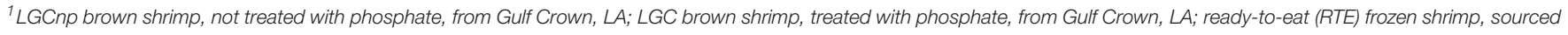

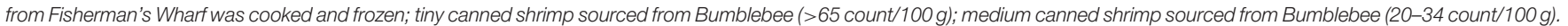

that calcium was higher in tiny and medium canned shrimp; higher calcium may result in increased shear force. Zinc is higher in medium canned shrimp compared with other products.

\section{CONCLUSIONS}

Real-time heat penetration data for shrimp in water to a target $F_{0}$ value of $6.0 \mathrm{~min}$ with and without reciprocal agitation was developed. In conclusion, reciprocal agitation thermal processing of canned shrimp resulted in superior product compared with static retort processing, improved process parameters, and potential energy savings. The time to reach the targeted $F_{0}$ value of 6 was achieved $42 \%$ faster at 180 SPM than 0 SPM. In addition, firmness of retort processed shrimp increased by $62 \%$ when processed at 180 SPM, compared with static retort thermal processing. Yield of retort processed shrimp remained high at $73 \%$. Integrity remained high with minimal, visible damage, and sloughing not impacting yield. Subjective color and overall appearance indicated that the shrimp processed with reciprocal agitation were superior to existing commercial, canned shrimp and comparable with frozen thawed products. Since firmness of shrimp processed at 90 or 180 SPM were similar, reciprocal agitation at $90 \mathrm{SPM}$ is recommended to achieve high retort efficiency and to provide a high-quality, canned shrimp that can be distributed and stored at ambient temperature. Additionally, the polypropylene injection IML oxygen barrier rigid plastic containers were not adversely affected by either static or reciprocal agitation thermal processing.

\section{REFERENCES}

Awuah, G. B., Ramaswamy, H. S., and Economides, A. (2007). Thermal processing and quality: principles and overview. Chem. Eng. Process. 46, 584-602. doi: 10.1016/j.cep.2006.08.004
Thermal processing of shrimp with reciprocal agitation offers an alternative preservation method to cold chain distribution, to provide high-quality, convenient, long-shelf, ready-to-eat shrimp. Future work should evaluate the sensory and analytical flavor profile, and other quality changes determined by an extended shelf life study.

\section{DATA AVAILABILITY STATEMENT}

The raw data supporting the conclusions of this article will be made available by the authors, without undue reservation, to any qualified researcher.

\section{AUTHOR CONTRIBUTIONS}

WD: methodology, data curation, statistical analysis, original draft preparation, and reviewing. EW: methodology, conceptualization, and reviewing. XF: conceptualization, methodology, and reviewing. JK: conceptualization, reviewing, editing, and funding. LW: conceptualization, writing, reviewing, editing, funding, and supervision. All authors contributed to the article and approved the submitted version.

\section{FUNDING}

The authors greatly acknowledged the partial funding and contributions of LSU AgCenter Hatch Project No. LAB94334 and Board of Regents Project No. 037 ENH-19. 
and limitations. J. Food Eng. 110, 208-213. doi: 10.1016/j.jfoodeng.2011. 05.034

Buzby, J. C., Wells, H. F., and Hyman, J. (2014). The Estimated Amount, Value and Calories of Postharvest Food Losses at the Retail and Consumer Levels in the United States. USDA Economic Research Service. Available online at: https://www.ers.usda.gov/data-products/food-availability-per-capita-datasystem/food-loss/ (accessed June 20, 2020).

Byun, Y., Hong, S. I., Mangalassary, S., Bae, H. J., Cooksey, K., Park, H. J., and Whiteside, S. (2010). The performance of organic and inorganic coated retort pouch materials on the shelf life of ready-to-eat rice products. Food Sci. Technol. 43, 862-866. doi: 10.1016/j.lwt.2010.01.009

Carneiro, C. D., Mársico, E. T., Ribeiro, R. D., Júnior, C. D., Álvares, T. S., and Oliveira De Jesus, E. F. (2013). Quality attributes in shrimp treated with polyphosphate after thawing and cooking: a study using physicochemical analytical methods and low-field H NMR. J. Food Process. Eng. 36, 492-499. doi: $10.1111 /$ jfpe. 12011

Erdogdu, F., Balaban, M. O., Otwell, W. S., and Garrido, L. (2004). Cook-related yield loss for pacific white (Penaeus vannamei) shrimp previously treated with phosphates: effects of shrimp size and internal temperature distribution. J. Food Eng. 64, 297-300. doi: 10.1016/j.jfoodeng.2003.10.012

Erdogdu, F., Tutar, M., Oines, S., Barreno, I., and Skipnes, D. (2016). Determining the optimal shaking rate of a reciprocal agitation sterilization system for liquid foods: a computational approach with experimental validation. Food Bioproducts Process. 100, 512-524. doi: 10.1016/j.fbp.2016.07.012

FAO (2011a). Global Food Losses and Food Waste. Extent, Causes and Prevention. Available online at: http://www.fao.org/3/a-i2697e.pdf (accessed May 29, 2020).

FAO (2011b). Food Loss and Waste in Fish Value Chains. Available online at: http://www.fao.org/flw-in-fish-value-chains/overview/objective/en/ (accessed June 4, 2020).

FAO (2013). "Codex standard for canned shrimps or prawns," in Codex Standard for Canned Shrimps or Prawns, ed Codex Alimentarius. Available online at: http://www.fao.org/fao-who-codexalimentarius/sh-proxy/en/?lnk=1\& url=https\%253A\%252F\%252Fworkspace.fao.org\%252Fsites\%252Fcodex \%252FStandards\%252FCXS\%2B37-1991\%252FCXS_037e.pdf

FAO (2015). Save Food: Global Initiative on Food Loss and Waste Reduction. Available online at: http://www.fao.org/3/a-i4068e.pdf (accessed June 14, 2020).

FAO (2019a). Globefish Highlights. April 2019. Available online at: http://www.fao. org/3/ca5307en/ca5307en.pdf (accessed June 4, 2020).

FAO (2019b). United States of America GLOBEFISH Profile. Available online at: http://www.fao.org/3/ca5212en/ca5212en.pdf (accessed June 4, 2020).

Goff, H. D. (2020). "Thermal destruction of microorganisms," in Thermal Destruction of Microorganisms, Dairy Science and Technology Education Series, 8. University of Guelph. Available online at: https://www.uoguelph.ca/ foodscience/industry/dairy-education-ebook-series

Hassan, H. E., and Ramaswamy, H. S. (2013). Bio-validation of biaxial rotary thermal processing. Food Sci. Technol. 53, 418-425. doi: 10.1016/j.lwt.2013.02.009

Heitkemper, D. T., Kaine, L. A., Jackson, D. S., and Wolnik, K. A. (1993). "Determination of tripolyphosphate and related hydrolysis products in processed shrimp," in 18th Annual Tropical and Subtropical Fisheries Technological Conference (Williamsburg, VA), 92-100.

Ling, B., Tang, J., Kong, F., Mitcham, E. J., and Wang, S. (2015). Kinetics of food quality changes during thermal processing: a review. Food Bioprocess Technol. 8, 343-358. doi: 10.1007/s11947-014-1398-3

Louisiana Agriculture (2017). "Louisiana summary agriculture and natural resources," in Louisiana Summary Agriculture and Natural Resources, ed Louisiana Cooperative Extension Service (Baton Rouge: LSU AgCenter), 11.

MacNaughton, M., Whiteside, W. S., Rieck, J. R., and Thomas, R. L. (2018). The effects of static, oscillating, and oscillating with dwell time retort motions on the rate of heat penetration of a food simulant. J. Food Process. Preserv. 42:e13410. doi: $10.1111 /$ jfpp. 13410

Majumdar, R. K., Deepayan, R., and Apurba, S. (2017). Textural and sensory characteristics of retort-processed freshwater prawn (Macrobrachium rosenbergii) in curry medium. Int. J. Food Prop. 20, 2487-2498. doi: 10.1080/10942912.2016.1242139

Mallick, A. K., Srinivasa Gopal, T. K., Ravishankar, C. N., Vijayan, P. K., and Geethalakshmi, V. (2010). Changes in instrumental and sensory properties of indian white shrimp in curry medium during retort pouch processing at different $\mathrm{F}_{0}$ values: changes in instrumental and sensory properties of shrimp. J. Texture Stud. 41, 611-632. doi: 10.1111/j.1745-4603.2010.00243.x

National Fisheries Institute (NFI) (2018). "Top 10 list shows significant increase in seafood consumption," in: Top 10 List Shows Significant Increase in Seafood Consumption. Washington, DC: National Fisheries Institute. Available online at: https://www.aboutseafood.com/press_release/top-10-listshows-significant-increase-in-seafood-consumption/

National Food Processors Association (1982). Thermal Processes for Low-Acid Foods in Metal Containers. Westport, CT: AVI Publishing Co.

National Marine Fisheries Service (2018). "Fisheries of the United States," in Fisheries of the United States, ed U.S. Department of Commerce (Washington, DC: NOAA Current Fishery Statistics No. 2017), xxvi.

Niamnuy, C., Devahastin, S., and Soponronnarit, S. (2007). Quality changes of shrimp during boiling in salt solution. J. Food Sci. 72, 289-297. doi: $10.1111 / j .1750-3841.2007 .00349 . x$

Ramaswamy, H. S. (1993). Come-up time effectiveness for process calculations involving thin-profile packages. J. Food Eng. 19, 109-117. doi: 10.1016/0260-8774(93)90037-K

Shah, M. A., Bosco, S. J. D., Mir, S. A., and Sunooj, K. V. (2017). Evaluation of shelf life of retort pouch packaged Rogan josh, a traditional meat curry of Kashmir, India. Food Packag. Shelf Life 12, 76-82. doi: 10.1016/j.fpsl.2017.04.001

Singh, A. P., and Ramaswamy, H. S. (2015). Effect of can orientation on heat transfer coefficients associated with liquid particulate mixtures during reciprocation agitation thermal processing. Food Bioprocess Technol. 8, 1405-1418. doi: 10.1007/s11947-015-1500-5

Singh, A. P., Singh, A., and Ramaswamy, H. S. (2016). A controlled agitation process for improving quality of canned green beans during agitation thermal processing. J. Food Sci. 81, 1399-1411. doi: 10.1111/1750-3841.13308

Singh, A. P., Singh, A., and Ramaswamy, H. S. (2017). Effect of reciprocating agitation thermal processing (RA-TP) on quality of canned tomato (Solanum lycopersicum) puree. J. Sci. Food Agric. 97, 2411-2418. doi: 10.1002/jsfa.8054

Singh, A. P., Yen, P. P. L., Ramaswamy, H. S., and Singh, A. (2018). Recent advances in agitation thermal processing. Curr. Opin. Food Sci. 23, 90-96. doi: 10.1016/j.cofs.2018.07.001

Sreenath, P. G., Abhilash, S., Ravishankar, C. N., and Gopal, T. K. S. (2008). Standardization of process parameters for ready-to-eat shrimp curry in tin-free steel cans. J. Food Process. Preserv. 32, 247-269. doi: $10.1111 / j .1745-4549.2008 .00177 . x$

Stoforos, N. G. (2010). Thermal process calculations through Ball's original formula method: a critical presentation of the method and simplification of its use through regression equations. Food Eng. Rev. 2, 1-16. doi: 10.1007/s12393-010-9014-4

Walden, R. (2008). "The Zinetec Shaka ${ }^{\mathrm{TM}}$ retort and product quality," in In-Pack Processed Foods, ed P. Richardson (Sawston: Woodhead Publishing), 86-101. doi: $10.1533 / 9781845694692.2 .86$

Walden, R., and Emanuel, J. (2010). "Developments in in-container retort technology: the Zinetec Shaka $\AA$ process," in Case Studies in Novel Food Processing Technologies, eds C. J. Doona, K. Kustin, and F. E. Feeherry (Sawston: Woodhead Publishing), 389-406. doi: 10.1533/978085709071 3.4.389

You, J., Singh, A. P., Singh, A., and Ramaswamy, H. S. (2016). Quality retention enhancement in canned potato and radish using reciprocating agitation thermal processing. Int. J. Food Eng. 12, 491-500. doi: 10.1515/ijfe-201 5-0276

\section{Conflict of Interest: JK was employed by company Apis Group, LLC.}

The remaining authors declare that the research was conducted in the absence of any commercial or financial relationships that could be construed as a potential conflict of interest.

Copyright $\odot 2020$ Dixon, Watts, King, Fu and Wicker. This is an open-access article distributed under the terms of the Creative Commons Attribution License (CC BY). The use, distribution or reproduction in other forums is permitted, provided the original author(s) and the copyright owner(s) are credited and that the original publication in this journal is cited, in accordance with accepted academic practice. No use, distribution or reproduction is permitted which does not comply with these terms. 